\title{
XXV. THE ESTIMATION OF CALCIUM.
}

\section{BY EDWARD CAHEN AND WILLIAM HOLDSWORTH HURTLEY.}

\author{
From the Chemical Laboratory, St Bartholomew's Hospital.
}

(Received May 24th, 1916.)

Some time ago Professor Andrewes [1915] was engaged in estimating the calcium in the aortas of normal and diseased persons. For that purpose the aortas were calcined until all organic matter was destroyed. After this operation the residue was worked up for the estimation of calcium by a slight modification of Aron's method [1907]. Certain aortas yielded a residue which only dissolved in strong sulphuric acid after many hours' heating. It was to overcome difficulties of this nature that the following method was devised. We found that a calcined residue which only dissolved in sulphuric acid after very prolonged heating would dissolve completely and in a few moments if heated with a solution of phosphoric acid of suitable strength. The calcium in such a solution can be estimated by the usual volumetric and gravimetric methods, which have for their basis the precipitation of calcium oxalate.

\section{The Method.}

Of a normal organ such as heart, or muscle, 100 grams of the substance are required; of an aorta rich in calcium very much less will suffice; of urine 100 cc. is a suitable quantity. The organ or tissue is dried at $100^{\circ}$ and incinerated in the usual way; the urine is eraporated at first on the water bath, then dried at $120^{\circ}$ and incinerated as before. To the residue a solution of phosphoric acid is added: if much calcium is present, 20 cc. of an acid of sp. gr. 1.2 (1 vol. syrupy phosphoric acid to 3 vols. water): if little, $10 \mathrm{cc}$. or even less. On warming, the calcium dissolves completely. This solution can be used direct for a volumetric determination, but it must be filtered and the residue washed for a gravimetric determination. The liquid is diluted 
with 50 or $100 \mathrm{cc}$. of water according to the amount of calcium present and then a solution of oxalic acid containing $37 \cdot 8$ g. $\mathrm{C}_{2} \mathrm{H}_{2} \mathrm{O}_{4} 2 \mathrm{H}_{2} \mathrm{O}$ per litre is added so as to afford about five times the theoretical amount of oxalic acid. Thus in practice if the amount of calcium is about $0 \cdot 2 \mathrm{~g}$. reckoned as calcium carbonate, $100 \mathrm{cc}$. of the oxalic acid would be added. Precipitation is rapid, and the precipitate is crystalline, but a little calcium remains in solution. To effect complete precipitation a volume of ammonia equal to the volume of the oxalic acid used is then added, the strength of the ammonia being exactly equivalent to that of the oxalic acid, namely $10 \cdot 2 \mathrm{~g}$. of $\mathrm{NH}_{3}$ per litre. If magnesium is present the ammonia must be added slowly and with shaking from a burette. The precipitated solution is allowed to stand for one hour: it will then filter quickly and perfectly clear. If ammonium oxalate be used, instead of oxalic acid followed by ammonia as above, the precipitate is far less crystalline and filters very badly.

\section{A. Volumetric Determination.}

In this method we make use of a small conical Buchner funnel so as to minimise the amount of washing needed to remove ammonium oxalate from the filter paper. Seven washings with cold distilled water are sufficient for this. The precipitate and paper are transferred to the same beaker in which the precipitation was effected; $10 \mathrm{cc}$. of sulphuric acid ( 1 vol. water : 1 vol. pure concentrated acid) are added; the solution heated nearly to boiling and titrated with decinormal permanganate. The sulphuric acid sometimes consumes a few drops of permanganate so that a blank experiment should be made.

\section{B. Gravimetric Determination.}

This is done in the usual way and needs no description.

\section{Results.}

As a check on the method we determined the percentage purity of a sample of commercial calcium carbonate sold as "Calcium Carbonate Reagent."

$4.84 \mathrm{~g}$. were dissolved in $25 \mathrm{cc}$. of syrupy phosphoric acid and made up to $250 \mathrm{cc}$. with water : $10 \mathrm{cc}$. were taken, and $50 \mathrm{cc}$. of water, $100 \mathrm{cc}$. of oxalic acid and 100 cc. of ammonia were added in every case. 


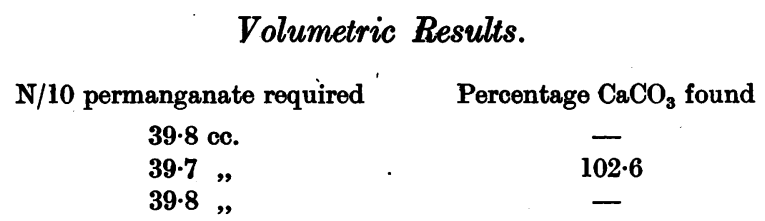

Gravimetric Results.

Weight of $\mathrm{CaO}$ obtained

$0 \cdot 1104$

0.1104

0.1102
Percentage $\mathrm{CaCO}_{3}$ found

$101 \cdot 8$

101.8

101.5

By solution of the carbonate in excess of hydrochloric acid and back titration by standard caustic soda we obtained in three experiments $100 \cdot 64$, $101 \cdot 08,101 \cdot 25$.

The sample evidently contained more calcium than corresponds to the formula $\mathrm{CaCO}_{3}$ : we found in fact that it contained some calcium hydroxide. By solution of some of the carbonate in hydrochloric acid and precipitation with ammonium carbonate, we obtained a specimen of really pure calcium carbonate which gave us a percentage of $100 \cdot 14$.

We now give examples of the determination of calcium in various substances by our own method and those of Aron [1907] and McCrudden [1910, 1911].

Urine. 100 cc. used in each experiment.

\begin{tabular}{ccc}
\multicolumn{3}{c}{ Percentage CaO. } \\
Our method & Aron's method & McCrudden's method \\
0.072 & 0.071 & 0.074 \\
0.045 & 0.044 & 0.045 \\
0.033 & 0.032 & 0.032 \\
0.041 & 0.033 & 0.040
\end{tabular}

Aorta. Portions of the same aorta were used for the determinations by us and by Professor Andrewes working independently.

- Percentage CaO in dried Aorta.

$\begin{array}{ccc} & \text { Our method } & \text { Andrewes by Aron's method } \\ \text { I } & 1.31 & 1.29 \\ \text { II } & 8.06 & 7.45 \\ \text { III } & 1.91 & 1.72\end{array}$




\section{Calcium in the presence of Magnesium.}

To test the validity of the method where calcium is accompanied by magnesium we determined these two elements in solutions, which contained a constant amount of calcium as oxide, and half, once and twice as much magnesium as oxide. The calcium was determined as described and the filtrate and washings from the calcium oxalate were concentrated to about 300 cc., 30 cc. of concentrated ammonia added and the mixture allowed to stand over night. The ammonium magnesium phosphate was then filtered off, washed, dried, ignited and weighed. Our first experiments were made with mixtures of calcium and magnesium phosphate and it appeared as if the magnesium were partly precipitated with the calcium oxalate for, as the proportion of magnesium rose from nought to twice the calcium, the amount of calcium increased: On testing the magnesium phosphate it was found to contain calcium. The use of phosphates was therefore abandoned and solutions of calcium and magnesium oxides in phosphoric acid were used. Of the calcium solution $10 \mathrm{cc}$. were used and $50 \mathrm{cc}$. of water added; but when calcium and magnesium were present together, $10 \mathrm{cc}$. of calcium solution and $150 \mathrm{cc}$. of water were used with 10,20 , and $30 \mathrm{cc}$. of the magnesium solution.

Results.

\begin{tabular}{|c|c|c|c|c|}
\hline \multirow{2}{*}{$\begin{array}{c}\text { cc. } \\
\mathrm{CaO}\end{array}$} & \multirow{2}{*}{$\begin{array}{l}\text { cc. } \\
\text { MgO }\end{array}$} & \multicolumn{2}{|c|}{$\mathrm{CaO}$ found } & \multirow[b]{2}{*}{$\mathrm{MgO}$ found } \\
\hline & & Volumetric & Gravimetric & \\
\hline 10 & 0 & $0 \cdot 1014$ & - & - \\
\hline 10 & 0 & $0 \cdot 1014$ & - & - \\
\hline 10 & 0 & - & $0 \cdot 1018$ & - \\
\hline 10 & 0 & - & $0 \cdot 1015$ & - \\
\hline 0 & 10 & - & - & 0.0537 \\
\hline 10 & 10 & $0 \cdot 1014$ & - & 0.0536 \\
\hline 10 & 10 & $0 \cdot 1015$ & - & 0.0532 \\
\hline 10 & 20 & $0 \cdot 1030$ & - & $0 \cdot 1081$ \\
\hline 10 & 20 & $0 \cdot 1025$ & - & $0 \cdot 1081$ \\
\hline 10 & 30 & $0 \cdot 1028$ & - & $0 \cdot 1625$ \\
\hline 10 & 30 & $0 \cdot 1025$ & - & $0 \cdot 1627$ \\
\hline 10 & 30 & - & $0 \cdot 1030$ & $0 \cdot 1625$ \\
\hline
\end{tabular}

The table shows that when the amount of magnesium as oxide exceeds the amount of calcium as oxide a little of the former is precipitated with the latter metal. In this case the precipitate of calcium oxalate is ignited, redissolved in a little phosphoric acid and precipitated again. This has always given us correct results. 
The ease with which calcium compounds dissolve in phosphoric acid might find application in several ways. For example we find that this acid enables us to make an excellent separation of calcium and barium sulphates; calcium sulphate readily dissolves but barium sulphate is quite insoluble in this acid.

Again calcium fluoride is soluble in the acid on heating. We have not examined this reaction quantitatively, but on testing the filtered solution with oxalic acid followed by ammonia abundance of typical calcium oxalate crystals were seen when the precipitate was examined under the microscope.

\section{REFERENCES.}

Andrewes (1915). Report of the Medical Officer L.G.B., 1913-1914, 179.

Aron (1907). Biochem. Zeitsch., 4, 268.

McCrudden (1910). J. Biol. Chem., 8, 83.

(1911). J. Biol. Chem., 10, 187. 